\title{
Antimicrobial High-Density Polyethylene (HDPE)/ZnO Nanocomposites Obtained by in situ Polymerization
}

\author{
Giovani Pavoski, ${ }^{a}$ Renan Kalikoski, ${ }^{a}$ Gustavo Souza, ${ }^{a}$ Daniel Baldisserotto, ${ }^{a}$ \\ Luiz Fernando W. Brum, ${ }^{a, b}$ Cristiane dos Santos, ${ }^{a}$ Carlos Bergmann, ${ }^{c}$ \\ Adriano Brandelli, ${ }^{b}$ Marly Jacobi ${ }^{a}$ and Griselda B. Galland ${ }^{\circledR} * a$
}

\author{
anstituto de Química, Universidade Federal do Rio Grande do Sul, \\ 91501-970 Porto Alegre-RS, Brazil \\ ${ }^{b}$ Instituto de Ciência e Tecnologia de Alimentos, Universidade Federal do Rio Grande do Sul, \\ Av. Bento Gonçalves 9500, 91501-970 Porto Alegre-RS, Brazil \\ ${ }^{c}$ Laboratório de Materiais Cerâmicos, Departamento de Materiais, \\ Universidade Federal do Rio Grande do Sul, 91501-970 Porto Alegre-RS, Brazil
}

\begin{abstract}
Nanostructured zinc oxide $(\mathrm{ZnO})$ prepared by combustion in solution was used to obtain nanocomposites. The $\mathrm{ZnO}$ particles were characterized by Brunauer-Emmett-Teller (BET), X-ray diffraction (XRD), and scanning electron microscopy (SEM), showing crystallite size of $32 \mathrm{~nm}$ and a superficial area of $32.6 \mathrm{~m}^{2} \mathrm{~g}^{-1}$. Nanocomposites with 1, 3, and $5 \mathrm{wt} . \%$ of $\mathrm{ZnO}$ in the polymeric matrix were obtained using the $i n$ situ polymerization of ethylene with catalytic activities between $1500-1700 \mathrm{~kg}\left(\mathrm{~mol}_{\mathrm{Zr}} \mathrm{h} \mathrm{P}_{\mathrm{E}}\right)^{-1}$. The high-density polyethylene nanocomposites (PEZnO) were characterized by thermogravimetric analysis (TGA), differential scanning calorimetry (DSC), SEM, and transmission electron microscopy (TEM). The nanocomposites with $1 \mathrm{wt} \% \mathrm{ZnO}$ gave excellent mechanical properties, and all were active against Gram-positive (Staphylococcus aureus) and Gram-negative (Escherichia coli) bacteria.
\end{abstract}

Keywords: zinc oxide, nanostructured, in situ polymerization, polyethylene, antimicrobial properties

\section{Introduction}

Recently, there has been significant progress in the development of new technologies related to antibacterial and antimicrobial coatings and composites due to the increasing concern regarding threats to public health (i.e., bacteria, fungi, and viruses). ${ }^{1}$

Zinc oxide $(\mathrm{ZnO})$ nanoparticles are considered good antimicrobial agents due to their safety, low toxicity, and biocompatibility towards humans, ${ }^{2}$ in addition to their advantage of being low-cost materials. ${ }^{3}$ The antibacterial mechanism of $\mathrm{ZnO}$ has been associated with the formation of reactive oxygen species (ROS), such as hydroxyl and superoxide radicals and $\mathrm{H}_{2} \mathrm{O}_{2}$, when nano- $\mathrm{ZnO}$ interacts with bacterial cells in the presence of moisture. Hydroxyl and superoxide radicals are negatively charged and cannot penetrate the cell membrane remaining in the outer surface

*e-mail: griselda.barrera@ufrgs.br of the bacteria, causing severe damage to surface lipids and proteins. On the other hand, $\mathrm{H}_{2} \mathrm{O}_{2}$ can penetrate the membrane and can kill the bacteria. ${ }^{4}$

The antibacterial activity of $\mathrm{ZnO}$ has been described against some Gram-positive and Gram-negative bacteria, such as Bacillus subtilis, Staphylococcus aureus, Pseudomonas aeruginosa, and Escherichia coli. However, Gram-negative bacteria often show less sensitivity to $\mathrm{ZnO}$ nanoparticles, probably due to differences in the membrane properties and reactivity toward ROS..$^{5}$ The decrease in particle size is another factor that influences antibacterial activity favored also by the increase in surface area. Other factors that influence the antibacterial effect are the morphology and surface characteristics of the particle, such as hydrophilicity or roughness. ${ }^{3,6}$

Polymeric nanocomposites with antimicrobial fillers have emerged as new alternatives for antibacterial agents, mainly because they are non-volatile and chemically stable materials. They can help avoid the contamination of food, 
water, and industrial equipment that may be contaminated by microorganisms. ${ }^{1}$ Biodegradable and biocompatible polymers and their nanocomposites find applications in medicine, such as in tissue engineering, drug delivery, and biosensors. Other polymers, such as polyethylene, are not biodegradable, but they are harmless and have excellent mechanical properties. These polymers can be combined with bioactive nanoparticles to create biocompatible nanocomposites (meaning non-toxic towards humans) that find applications in medicine as syringes, catheters, pharmaceutical bottles, bags, health foils, or nonwovens. ${ }^{6}$ Antimicrobial agents incorporated into a polymer limit or prevent microbial growth, which could have applications in packaging to extend shelf life of packaged food in the form of films, containers, or utensils. ${ }^{7,8}$

Furthermore, polymeric nanocomposites with $\mathrm{ZnO}$ as the filler have been prepared with various polymers, ${ }^{9-11}$ by different methods, targeting several properties. The next bibliographic research is concentrated in polyethylene $(\mathrm{PE}) / \mathrm{ZnO}$ nanocomposites that is the subject of this work. Hong et al. ${ }^{12}$ found significant dielectric properties in $\mathrm{ZnO} /$ low-density polyethylene (LDPE) nanocomposites. Alam et al. ${ }^{13}$ observed the increase in the hardness of ultra-high molecular weight polyethylene (UHMWPE) with the addition of $\mathrm{ZnO}$ nanoparticles. Nano- and micro-ZnO particles have been used in linear low-density polyethylene (LLDPE) as heat sinks due to their effects as antistatic agents, although $\mathrm{ZnO}$ decreased the toughness and increased the brittleness and stiffness in the polymer matrix. ${ }^{14}$ The optical properties of high-density polyethylene (HDPE)/ZnO nanocomposites have been studied by other researchers. ${ }^{15,16}$ These materials showed high tensile strength, ultraviolet (UV) absorption properties, and transparency in the visible region, as required for packaging materials. LDPE/ZnO composites with mean particle sizes on the order of $770 \mathrm{~nm}$ showed antimicrobial activity against Escherichia coli and Staphylococcus aureus. ${ }^{7}$ Recently, Zapata and co-workers ${ }^{17}$ obtained LDPE/ZnO and LDPE/ZnO modified with oleic acid by melt compounding. The nanocomposites showed increase of Young's modulus and antimicrobial properties against Escherichia coli.

Composites can be strongly affected by the morphology and size of the inorganic particles and their dispersion in the polymer matrix, thus, the methods used in the preparation of the inorganic particles and the composites are very important. Until now, the method for preparation of HDPE or LDPE composites or nanocomposites with $\mathrm{ZnO}$ has been the melt-mixing method, ${ }^{7,12,14-16}$ and for UHMWPE ${ }^{3,13}$ the method has been compression molding.

However, direct mixing of $\mathrm{ZnO}$ nanoparticles with polyethylene $(\mathrm{PE})$ by the melt-mixing method is inadequate due to the different natures of the materials. One is hydrophilic $(\mathrm{ZnO})$ and the other is hydrophobic (PE), which leads to agglomeration and poor dispersion. Other approaches have been used, such as first preparing an HDPE/polyethylene oxide (PEO) blend by melt-mixing and extracting the PEO to create a template polymer before impregnating with $\mathrm{ZnO}$ to improve dispersion and phase compatibility. The authors ${ }^{18}$ found some improvement in the Young's modulus, while the thermal properties and permeability were not significantly changed. $\mathrm{ZnO}$ was treated and co-mixed with stearic acid (SA) at a ratio of $50 / 50 \mathrm{wt} . \%$ and the mixture was then melt mixed to the HDPE matrix with various $\mathrm{ZnO}$ contents $(0.5,1$ and $2 \mathrm{wt} . \%)$ showing better dispersion than the untreated nanofiller. ${ }^{19}$ $\mathrm{ZnO}$ particles coated with silane coupling agents were mixed with LDPE to alter the dielectric behavior of the nanocomposites. ${ }^{12}$ Silane-treated $\mathrm{ZnO}$ nanoparticles with different loadings, from 0 to $20 \mathrm{wt} . \%$, were mixed with UHMWPE using a dry mechanical ball mill and they were hot-pressed. The incorporation of nano- $\mathrm{ZnO}$ with the UHMWPE demonstrated antibacterial activity against E. coli and S. aureus. ${ }^{20}$

However, the method of in situ polymerization, that is, ethylene polymerization in the presence of $\mathrm{ZnO}$, can offer better possibilities to attain a good dispersion of nanoparticles. This method is also interesting because with the introduction of the filler during the polymerization, the nanocomposite can be obtained in a single step, which is a big advantage over other methods that need a second step (mixing of the polymer with the filler at high temperatures, which implies high cost in energy and equipment). This method has not been attempted yet with a $\mathrm{ZnO}$ filler.

The objective of this work was to synthesize polyethylene (HDPE)/ZnO nanocomposites by in situ polymerization in order to obtain a good distribution of the nanofiller in the polymeric matrix and to evaluate the mechanical, thermal, and antibacterial properties of the resulting nanocomposites. The use of a metallocene catalyst allows greater control of the polymer structure. ${ }^{21}$ Bis(cyclopentadienyl) zirconium dichloride $\left(\mathrm{Cp}_{2} \mathrm{ZrCl}_{2}\right)$ catalyst was chosen because it is the simplest and cheapest among metallocenes, which facilitates synthesis and it was used with success in our previous works ${ }^{22,23}$ with polyethylene/silica-silver ( $\mathrm{PE} / \mathrm{SiAg}$ ) nanocomposites.

\section{Experimental}

Nanometric zinc oxide preparation

Nanostructured $\mathrm{ZnO}$ was synthesized by combustion in solution. ${ }^{24}$ The reagents used were zinc nitrate, 
$\mathrm{Zn}\left(\mathrm{NO}_{3}\right)_{2} \cdot 6 \mathrm{H}_{2} \mathrm{O}$ (practical grade (p.a.), Labsynth, Diadema, Brazil), amino acetic acid p.a. (glycine) (Vetec, Rio de Janeiro, Brazil), and deionized water. The precursors, hydrated zinc nitrate p.a. (14.87 g) and glycine $\geq 98.5 \%$ $(1.04 \mathrm{~g})$, were mixed in approximately $100 \mathrm{~mL}$ of deionized water (enough for dissolution). The solution was heated to a temperature of $50{ }^{\circ} \mathrm{C}$ under constant stirring on a heating magnetic plate for a period of approximately $10 \mathrm{~min}$ to ensure total homogenization of the solution. Then, the temperature was elevated to $500{ }^{\circ} \mathrm{C}$ for the combustion procedure to obtain the nanostructured $\mathrm{ZnO}$.

The crystallographic phases and crystallite sizes were determined using the X-ray diffractometer PHILIPS (X'Pert MPD model), equipped with a graphite monochromator, $\mathrm{Cu} \mathrm{K} \alpha$ radiation $(\lambda=1.5406 \AA)$ and fixed anode operated at $40 \mathrm{kV}$ and $40 \mathrm{~mA}$. The size of crystallite was calculated with the WinFit software. ${ }^{25}$ This software performs an adjustment in the experimental peaks using asymmetric Pearson VII functions, corrects the instrumental enlargement and breaks down the peaks into two components: Gaussian and Lorentzian. The Gaussian contribution characterizes the effect in crystallite size and the Lorentzian contribution characterizes the effect of deformation on the width of the diffraction. Thus, the size of the crystallites can be calculated determining the specific Pearson VII functions for each maximum diffraction. ${ }^{26,27}$

The specific surface area was determined by the Brunauer-Emmett-Teller (BET) method using a Quantachrome (NOVA1000 Autosorb Automated Gas Sorption System, Boynton Beach, FL, USA). ${ }^{28}$

\section{HDPE/ZnO nanocomposite preparation}

The nanocomposites were obtained by in situ polymerization in a $100 \mathrm{~mL}$ Parr reactor. The catalyst system used to polymerize ethylene was bis(cyclopentadienyl) zirconium dichloride $(\geq 98.5 \%)\left(\mathrm{Cp}_{2} \mathrm{ZrCl}_{2}\right)$ (SigmaAldrich, São Paulo, Brazil) in the amount of $4 \times 10^{-6} \mathrm{~mol}$ and methylaluminoxane (MAO, $10 \mathrm{wt} . \% \mathrm{Al}$ solution in toluene) (Sigma-Aldrich, São Paulo, Brazil) as a co-catalyst and scavenger at a ratio of $\mathrm{Al} / \mathrm{Zr}=1000$. Toluene p.a. was used as the solvent at $40{ }^{\circ} \mathrm{C}$. Ethylene (3.0 bar) was the monomer, and the reaction was run for $30 \mathrm{~min}$.

$\mathrm{ZnO}$ was dispersed in toluene (previous addition to the reactor) in a Schlenk vessel under an inert atmosphere. Then, MAO solution $(0.1 \mathrm{~mL})$ was added and stirred with a magnetic bar for $15 \mathrm{~min}$. The suspension was then stirred for another $15 \mathrm{~min}$ in an ultrasound bath. Four different products were prepared: high density polyethylene zinc oxide (PEZnO) nanocomposites with 1 wt. $\% \mathrm{ZnO}$ (1\% PEZnO), 3 wt. \% (3\% PEZnO), and 5 wt. \%
(5\% PEZnO) and high-density polyethylene without filler (PE). Addition of the reagents in the reactor took place in the following order: toluene $(50 \mathrm{~mL}), \mathrm{MAO}(2.3 \mathrm{~mL})$, filler ( $\mathrm{ZnO}$ in variable amounts), catalyst, and ethylene. The polymerization reactions were stopped using acetone.

\section{Nanocomposite characterization}

Thermogravimetric analysis (TGA) was performed on an SDT Q600 thermal analyzer Q20 (TA Instruments) at a scanning rate of $20{ }^{\circ} \mathrm{C} \mathrm{min}-1$ from 25 to $700{ }^{\circ} \mathrm{C}$ in inert atmosphere.

The melting temperature and crystallinity of the nanocomposites were measured using a differential scanning calorimeter (TA Instruments Q20) with a heating rate of $10^{\circ} \mathrm{C} \mathrm{min}^{-1}$ and a temperature range of $20-160{ }^{\circ} \mathrm{C}$. The heating cycle was performed twice to remove the thermal memory of the material, and only the results of the second heating were considered. The degree of crystallinity $(\mathrm{Xc})$ was calculated from the enthalpy of fusion $\left(\mathrm{DH}_{\mathrm{f}}\right)$ obtained from the differential scanning calorimetry (DSC) curves using the equation: $\mathrm{Xc}=\left(\mathrm{DH}_{\mathrm{f}} / \Delta \mathrm{H}_{\mathrm{f}}^{\circ}\right) \times 100$ (the enthalpy of fusion $\Delta \mathrm{H}_{\mathrm{f}}^{\circ}=293.9 \mathrm{~J} \mathrm{~g}^{-1}$ was used for $100 \%$ crystalline polyethylene). ${ }^{29}$

The water contact angle test was carried out using the sessile drop method, where a $2-\mu \mathrm{L}$ drop of deionized water at room temperature was steadily deposited on the surface of the neat PE matrix and its nanocomposites using a microsyringe. The images were captured using drop shape analysis (DSA) system equipment (Kruss, DSA100). Each measurement was repeated at least five times at different positions. A digital video camera was used to capture the images that were analyzed by Surftens 3.0 software $^{30}$ for contact angle measurements.

Scanning electron microscopy (SEM) was performed using a Carl Zeiss SEM (model EVO MA10) operating at 7 and $15 \mathrm{kV}$, with aluminum stubs and gold metallization.

Transmission electron microscopy (TEM) images were obtained using a Tecnai G2 T20 TEM (FEI Company) operating at $8 \mathrm{kV}$. All samples were prepared by solubilizing the nanocomposites in decalin (p.a., Neon Commercial, São Paulo, Brazil) with heating at $70^{\circ} \mathrm{C}$. A drop of decalin solution was placed on a copper grid covered with ultrafine amorphous carbon film.

The nanocomposite films used to measure the properties were obtained by melt-pressing at 30 to $35^{\circ} \mathrm{C}$ above the melting point of the sample. The test specimens used for the mechanical property tests had $50-\mathrm{mm}$ gauge lengths and 10-mm widths, and for the antibacterial tests film discs with 20-mm diameters were obtained. The thickness of all films was in the range of 0.20 to $0.30 \mathrm{~mm}$. 
The molecular weight of neat polyethylene was obtained by gel permeation chromatography (GPC) with a Waters Alliance GPC 2000 instrument equipped with three Styragel HT-type columns (HT3, HT5, and HT6E). 1,2,4-Tricholobenzene was used as solvent, at a flow rate of $1 \mathrm{~mL} \mathrm{~min}^{-1}$ and at temperature of $135^{\circ} \mathrm{C}$. The columns were calibrated with polystyrene standards.

The mechanical properties were measured using an HP model D-500 dynamometer according to ASTM D638-10 $0^{31}$ at ca. $25{ }^{\circ} \mathrm{C}$. Five samples were tested for each wt. $\%$ of the nanocomposite, and the results were the average value of these five measurements (typical deviation of ca. 5\%). The bone-shaped samples had an overall length of $120 \mathrm{~mm}$, with a distance between the two grips of $80 \mathrm{~mm}$, a width of $11.5 \mathrm{~mm}$, and a thickness of $1 \mathrm{~mm}$ at the cross head. A rate of $50 \mathrm{~mm} \mathrm{~min}^{-1}$ was tested.

The antibacterial activity was evaluated against two bacteria, Staphylococcus aureus ATCC 1901 (Gram-positive) and Escherichia coli ATCC 8739 (Gram-negative). Bacteria were cultured in brain heart infusion (BHI) broth at $37^{\circ} \mathrm{C}$. A bacterial lawn culture was prepared by spreading $100 \mu \mathrm{L}$ culture broth $\left(10^{7}\right.$ colony forming unit (CFU) $\mathrm{mL}^{-1}$ ) for each test organism on solid $\mathrm{BHI}$ agar plates using the swab technique.

The antimicrobial activity of $\mathrm{ZnO}$ nanoparticles was tested using the agar well diffusion method. $\mathrm{ZnO}$ nanoparticles $(5 \mathrm{mg})$ were placed in $9-\mathrm{mm}$ diameter holes cut into the agar plates, which were incubated for $24 \mathrm{~h}$ at $37^{\circ} \mathrm{C}$. The diameters of the inhibition zones were measured, and the values are expressed as means \pm standard deviations of three independent experiments.

The antimicrobial activity of PEZnO nanocomposites was evaluated by the disc diffusion method. Film discs, 10 and 20-mm in diameter, were placed onto BHI agar plates previously inoculated with the bacteria, and they were incubated for $24 \mathrm{~h}$ at $37{ }^{\circ} \mathrm{C}$. Neat PE films were used as negative controls. After incubation, the presence or absence of inhibition zones was observed before and after removal of film samples. Each sample was evaluated through three independent experiments.

\section{Results and Discussion}

The $\mathrm{ZnO}$ nanostructured particles were characterized by SEM, X-ray diffraction (XRD), and BET. Figure 1 presents the SEM image of $\mathrm{ZnO}$ nanostructured particles. The formation of agglomerated particles is fully in accordance with the Ostwald ripening maturation theory in which larger particles grow at the expense of smaller particles. ${ }^{32}$

The formation of a pure crystalline phase $(\mathrm{ZnO})$ can be seen in the X-ray diffractogram in Figure 2. XRD

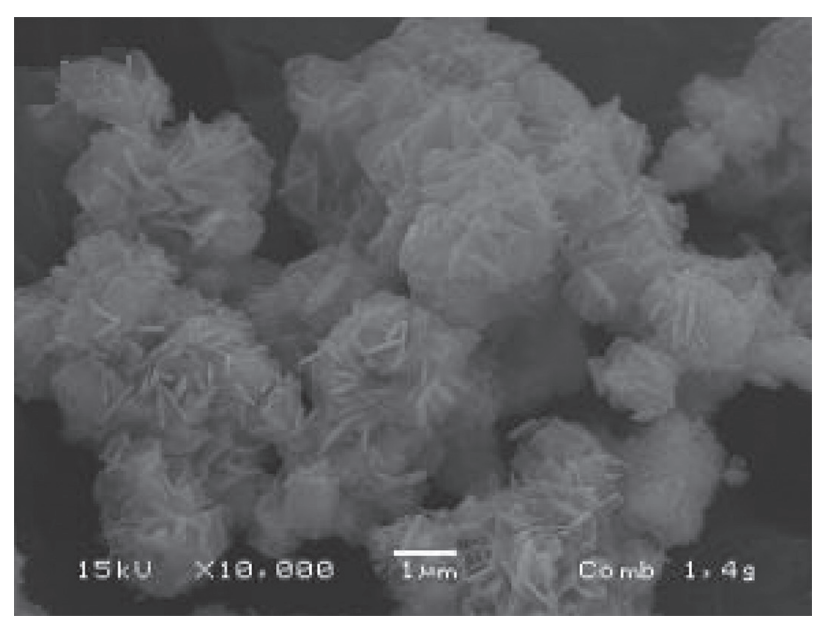

Figure 1. SEM image of $\mathrm{ZnO}$ nanostructured particles synthesized by combustion in aqueous glycine-nitrate solution.

results showed peaks at $2 \theta$ values of $31.8,34.5,36.2$, 47.6, 56.6, 62.9, 66.4, 67.9, and 69.1 degrees, typical for the hexagonal $\mathrm{ZnO}$ wurtzite structure. ${ }^{15}$ The crystallite size was around $32 \mathrm{~nm}$, showing that the synthesized $\mathrm{ZnO}$ was nanometric with a size slightly superior to the one prepared by Zapata and co-workers ${ }^{17}$ by sol-gel method that was of $17 \mathrm{~nm}$, but with an inferior size than other $\mathrm{ZnO}$ used in the literature ${ }^{7,20}$ for antimicrobial applications and similar to the size obtained by Javed et al. ${ }^{2}$ using the co-precipitation method. BET results gave a superficial area of $32.6 \mathrm{~m}^{2} \mathrm{~g}^{-1}$.

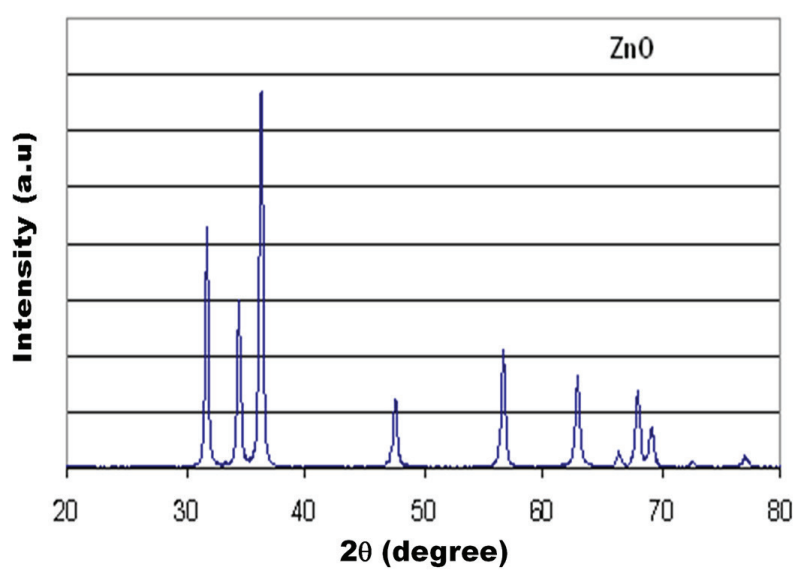

Figure 2. X-ray diffraction profile for the $\mathrm{ZnO}$ phase obtained by combustion.

The results of the polymerization reactions are shown in Table 1. Nanocomposites with nanofiller amounts close to 1,3 , and $5 \mathrm{wt} . \%$ were obtained. The amount of $\mathrm{ZnO}$ in the polymer (column 2) was calculated using the nanoparticles added (column 3) and the yield of polymer (column 4), and also using the TGA residue (column 8). The nanocomposite with 3\% of $\mathrm{ZnO}$ gave higher value of filler by TGA than by the yield, showing some heterogeneity in the distribution of $\mathrm{ZnO}$ particles in this sample. 
Table 1. Polymerization results. Catalytic activities and thermal properties

\begin{tabular}{lcccccccccc}
\hline Sample & $\mathrm{ZnO}^{\mathrm{a}} / \%$ & $\mathrm{ZnO} / \mathrm{g}$ & $\mathrm{Yield} / \mathrm{g}$ & $\begin{array}{c}\text { Catalytic activity } / \\
\left(\mathrm{kg}\left(\mathrm{mol}_{\mathrm{Zr}} \mathrm{h} \mathrm{P}_{\mathrm{E}}\right)^{-1}\right)\end{array}$ & $\mathrm{T}_{\text {onset }} /{ }^{\circ} \mathrm{C}$ & $\mathrm{T}_{\max } /{ }^{\circ} \mathrm{C}$ & $\mathrm{ZnO}^{\mathrm{b}} / \%$ & $\mathrm{Tc} /{ }^{\circ} \mathrm{C}$ & $\mathrm{Tm} /{ }^{\circ} \mathrm{C}$ & $\mathrm{Xc} / \%$ \\
\hline PE & 0 & 0 & 8.56 & 1902 & 285 & 485 & 0 & 117 & 129 \\
$1 \%$ PEZnO & 1.1 & 0.07 & 6.84 & 1520 & 272 & 485 & 1.1 & 120 & 131 & 55 \\
$3 \%$ PEZnO & 2.8 & 0.21 & 7.64 & 1698 & 279 & 485 & 5.7 & 119 & 131 & 53 \\
$5 \%$ PEZnO & 4.8 & 0.35 & 7.28 & 1618 & 273 & 488 & 5.9 & 118 & 131 & 55 \\
\hline
\end{tabular}

${ }^{\mathrm{a} C}$ alculated from polymer yield: $\mathrm{ZnO}(\%)=\mathrm{ZnO}(\mathrm{g}) \times 100 /$ Yield $(\mathrm{g})$; ${ }^{\mathrm{b}}$ calculated from TGA residues after subtraction of the residue obtained in the polymerization of neat PE. PE: polyethylene; $\mathrm{T}_{\text {onset }}$ : initial degradation temperature; $\mathrm{T}_{\max }$ : maximum degradation temperature; Tc: crystallization temperature; $\mathrm{Tm}$ : melting temperature; Xc: percentage of crystallinity.

One of the difficulties of the in situ polymerization is the deactivation of the catalyst by the polar groups of the filler, for this reason $\mathrm{ZnO}$ was previously impregnated with MAO. The catalytic activities of the reactions were all high and in the same order to the ones obtained in previous works $^{22,23}$ that used the same catalytic system. Due to the high sensibility of the catalyst to impurities the catalytic activities error can be between $10-15 \%$, so the catalytic activities obtained can be considered, also similar to the ethylene polymerization without filler, showing that MAO treatment was efficient, and the catalytic system was not deactivated by the presence of $\mathrm{ZnO}$.

The stability of the nanocomposites observed by TGA showed behavior similar to the neat polymer (TGA and TGA derivatives are included in the Supplementary Information (SI) as Figures S1 and S2). The crystallization (Tc) and melting $(\mathrm{Tm})$ temperatures of the nanocomposites were 1 to 3 degrees higher than those of neat polyethylene, and the percentage of crystallinity (Xc) about $10 \%$ higher in the nanocomposites, showing the nucleation power of $\mathrm{ZnO}$ that favors polymer crystallization. Higher crystallization temperatures are important for industry because they allow a reduction of the processing cycle, thus increasing the production rate. ${ }^{33}$ In contrast, $\mathrm{HDPE} / \mathrm{ZnO},{ }^{18}$ LLDPE/ZnO ${ }^{8}$ and $\mathrm{LDPE} / \mathrm{ZnO}^{17}$ prepared by the traditional melt-mixing method did not show any change in the melting or crystallization behavior. DSC curves are included in the SI section as Figures S3 to S6.

The SEM images (Figure 3) of the $\mathrm{ZnO}$ nanofiller (Figures $3 \mathrm{a}$ and $3 \mathrm{~b}$ ) and the nanocomposite with $1 \%$ of $\mathrm{ZnO}$ (Figures $3 \mathrm{c}$ and $3 \mathrm{~d}$ ) showed that the nanocomposites replicate the morphology of the filler. These micrographs also show a uniform distribution of the $\mathrm{ZnO}$ particles in the polymer matrix, which is corroborated by the TEM images (Figure 4), where it can also be seen that the nanoparticles (black spots) are dispersed in the polymer.

The weight average molecular weight $(\mathrm{Mw})$ of neat polyethylene obtained in this work was $177000 \mathrm{~g} \mathrm{~mol}^{-1}$ and the molecular weight distribution (MWD) 2.9 (the chromatogram is included in the SI section as Figure S7), which is typical for a polymer made with a metallocene catalyst. The molecular weights of the nanocomposites were not performed due to the deleterious effect of the nanoparticles in the GPC columns. Previous results ${ }^{34,35}$ showed that the nanocomposites retain the same $\mathrm{Mw}$ and MWD than the neat polymer when the filler is fed directly in the reactor (non-supported in the catalyst). Mw only increases in the nanocomposites when the catalyst is previously supported in the filler, ${ }^{36}$ which it is not the case in this work. Molecular weights are very sensitive to temperature when metallocene catalysts are used, ${ }^{37}$ thus in order to obtain a polyethylene with a high $\mathrm{Mw}$, a low polymerization temperature $\left(40{ }^{\circ} \mathrm{C}\right)$ was used. It is important for a polymer with weak intermolecular forces as polyethylene to present an $\mathrm{Mw}$ at least higher than 80000 to avoid the dependence of the mechanical properties on molecular weight. ${ }^{38}$

The mechanical properties were studied to determine the influence of $\mathrm{ZnO}$ nanoparticles on the elastic modulus, elongation at break, and ultimate tensile stress. As observed in Table 2 and Figure 5, the elastic modulus increased 13 and $21 \%$ with 1 and $3 \% \mathrm{ZnO}$ in the polyethylene matrix, respectively, and there was a slight decrease with a higher amount of filler. $\mathrm{ZnO}$ increases the rigidity of the polyethylene matrix, and this behavior goes along with a decrease in the elongation at break and the resistance to stress (ultimate tensile strength). As can be seen with $1 \% \mathrm{ZnO}$, the material still has good deformation (only $5 \%$ inferior to the original material). With the addition of a higher amount of filler (3\%), the elongation at break decreases $49 \%$, and with $5 \%$ the material becomes quite brittle, decreasing the elongation by $85 \%$. The decrease in the elongation of the composite is because the nanoparticles strongly restrict the movement of the polymer chains, thus preventing them from stretching when they are under stress. ${ }^{39}$ The decrease in elongation at break is higher when the agglomeration of the nanoparticles increases as it occurs at higher amount of filler. This means that if the objective 

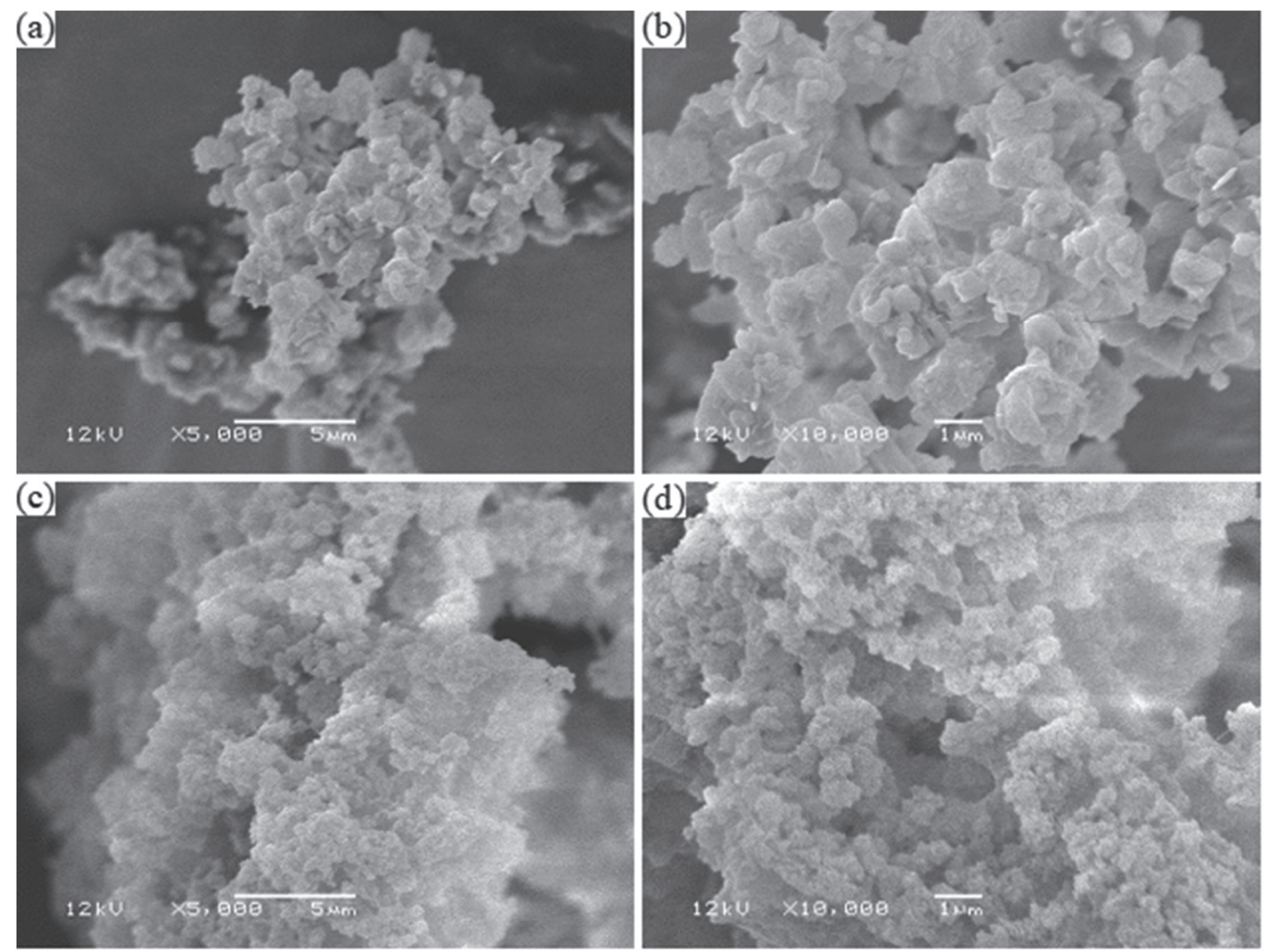

Figure 3. SEM images of the (a, b) ZnO nanofiller and the (c, d) 1\% PEZnO nanocomposites at 5000× and 10000× magnification, respectively.
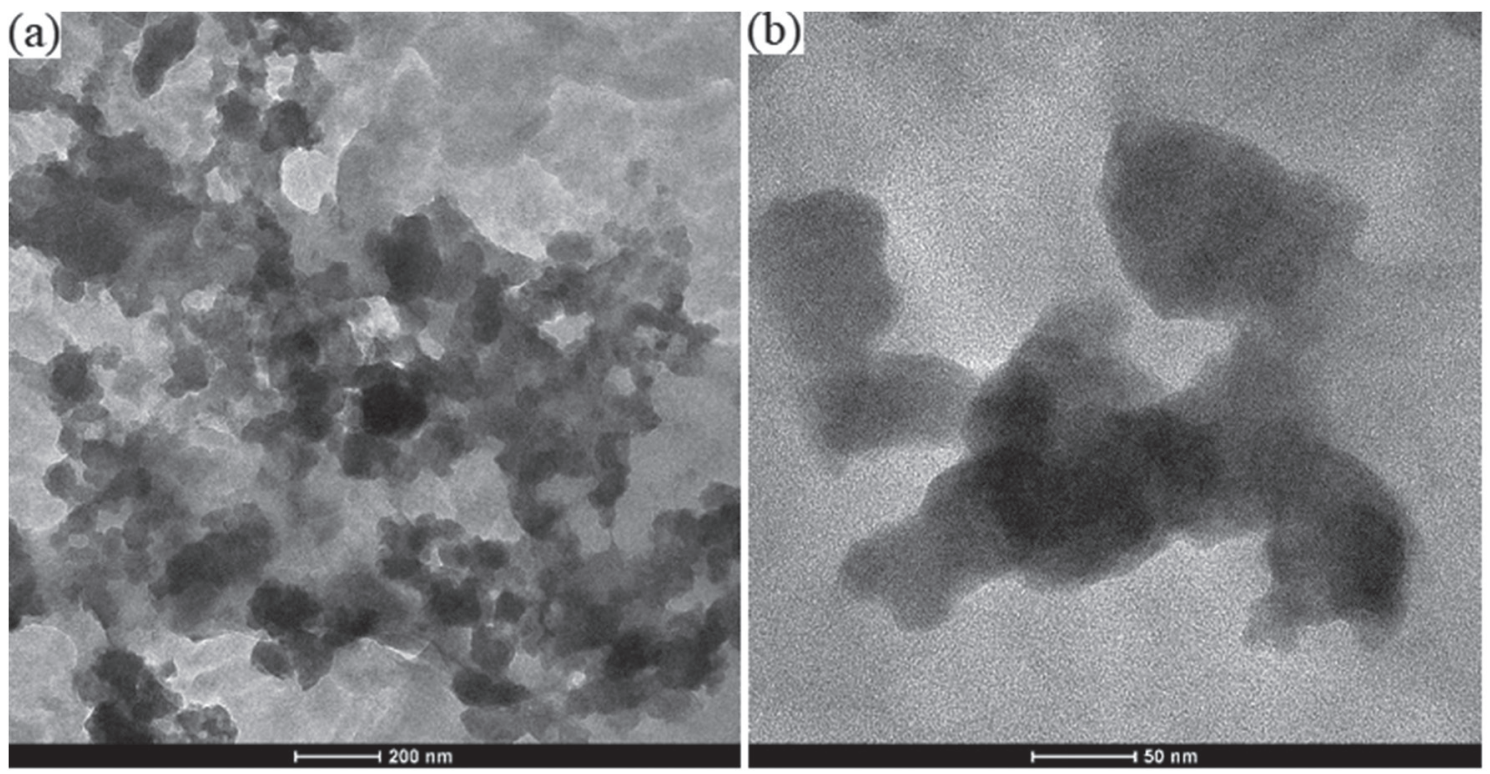

Figure 4. TEM images of the $3 \%$ PEZnO nanocomposite. (a) $\mathrm{Bar}=200 \mathrm{~nm}$ and (b) bar $=50 \mathrm{~nm}$.

is to maintain the mechanical properties of polyethylene, it should not be added to the polymer more than $1 \%$ of $\mathrm{ZnO}$.

The results obtained by in situ polymerization are very significant compared with HDPE/ZnO prepared by the melt-mixing method, which showed a decrease, instead of an increase in the Young modulus of 5\%, with similar amounts of $\mathrm{ZnO}$. When the melt-mixing method was used, the elongation at break decreased $10 \%$ with 1.5 wt. $\%$ ZnO. ${ }^{18}$ In LDPE/ZnO nanocomposites obtained by melt compounding, ${ }^{17}$ the Young's modulus increase was of $9 \%$ 
Table 2. Mechanical properties of polyethylene and PEZnO nanocomposites

\begin{tabular}{lccc}
\hline Sample & Elastic modulus / MPa & Elongation at break / \% & Ultimate tensile stress / MPa \\
\hline PE & $988 \pm 80$ & $537 \pm 47$ & $34 \pm 3$ \\
$1 \%$ PEZnO & $1116 \pm 106$ & $510 \pm 22$ & $29 \pm 8$ \\
$3 \%$ PEZnO & $1195 \pm 144$ & $273 \pm 10$ & $25 \pm 12$ \\
$5 \%$ PEZnO & $974 \pm 58$ & $80 \pm 29$ & $19 \pm 5$ \\
\hline
\end{tabular}

PE: polyethylene.

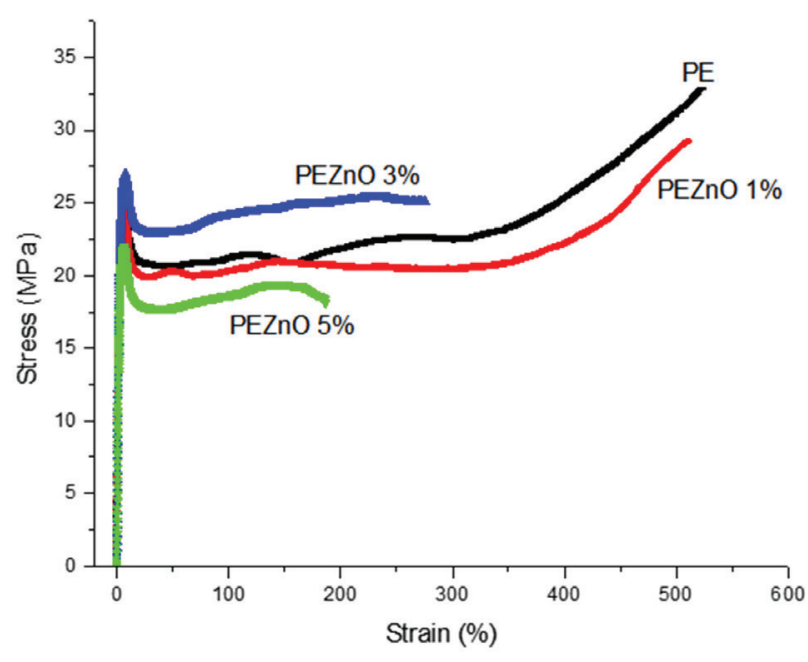

Figure 5. Stress-strain curves of polyethylene and PEZnO nanocomposites. for an incorporation of $\mathrm{ZnO}$ of $3 \%$, also inferior to the one obtained by in situ polymerization for the same amount of particles incorporation.

The $\mathrm{ZnO}$ nanoparticles did not present significant antimicrobial activity against $S$. aureus and $E$. coli, when tested in agar plates by the well diffusion method (there was not migration of $\mathrm{Zn}$ ions). The nanocomposites and neat polyethylene film samples were tested with respect to their antimicrobial activity against $S$. aureus and E. coli. The films placed onto agar plates inoculated with the bacteria were removed after $24 \mathrm{~h}$, and the presence or absence of bacterial growth was evaluated. The results are depicted in Figure 6, showing the effects against $S$. aureus (Figures $6 \mathrm{a}$ and $6 \mathrm{~b}$ ) and E. coli (Figures $6 \mathrm{c}$ and 6d). Bacterial growth was not inhibited when the control
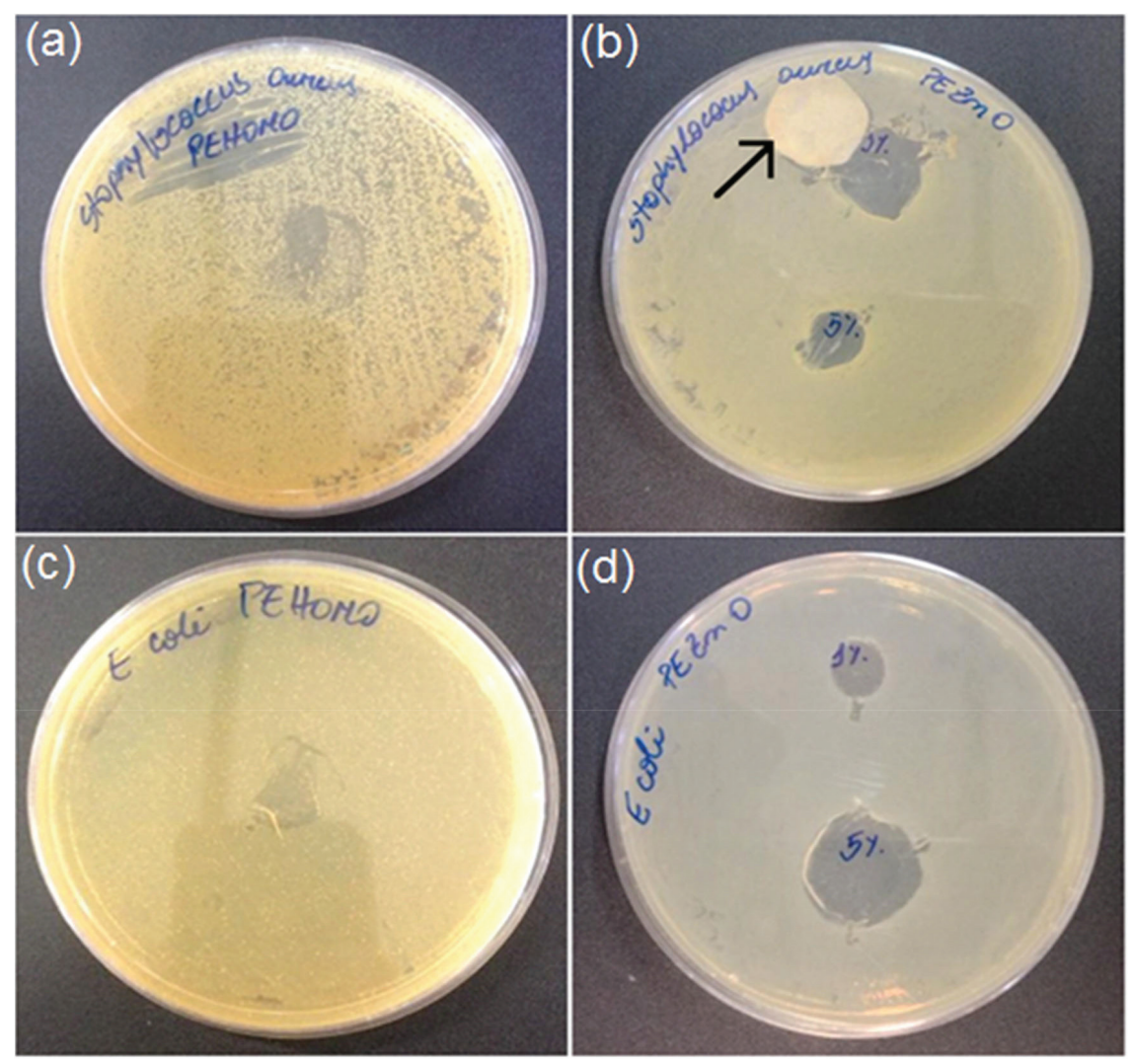

Figure 6. Antibacterial tests comparing neat polyethylene films (a, c) and PEZnO nanocomposites with 1 or $5 \%$ ZnO (b, d) against Staphylococcus aureus (a, b) and Escherichia coli (c, d). The arrow in (b) shows a $20 \mathrm{~mm}$ PEZnO film sample displaced from the contact area after $24 \mathrm{~h}$ incubation at $37^{\circ} \mathrm{C}$. 
films of neat polyethylene were evaluated (Figures 6a and $6 c)$. However, for the nanocomposites containing either 1 or $5 \% \mathrm{ZnO}$ the bacteria did not proliferate, indicating the inhibitory action of $\mathrm{ZnO}$ (Figures $6 \mathrm{~b}$ and $6 \mathrm{~d}$ ). In addition, the inhibition diameters were always limited to the contact area of the PEZnO films, suggesting that $\mathrm{ZnO}$ diffusion through the agar matrix was negligible, this behavior was already observed in our previous works ${ }^{22,23}$ with SiAg fillers. It has been seen that in nanocomposites of UHMWPE/ZnO the inhibition area has only some significance when $20 \%$ of $\mathrm{ZnO}$ were used. ${ }^{20}$ This result could be advantageous for packaging applications by reducing potential undesirable effects caused by migration of $\mathrm{ZnO}$ to the product.

Since $\mathrm{ZnO}$ is hydrophilic and PE is hydrophobic, the antibacterial activity could be due to a change in the hydrophilicity of the surface samples. If the presence of $\mathrm{ZnO}$ makes the film more hydrophilic, it is possible that the bacteria could adhere to the film surface and not proliferate. To study this effect, the water contact angles (WCA) of PE and $\mathrm{ZnO}$ nanocomposites were obtained (Table 3). As can be seen, there is no difference between the contact angles of PE $\left(\mathrm{WCA}=90.4 \pm 0.3^{\circ}\right)$ and $1 \% \mathrm{PEZnO}$ $\left(\mathrm{WCA}=89.2 \pm 7.7^{\circ}\right)$; however, the nanocomposites present antibacterial activity. The nanocomposite with the highest amount of $\mathrm{ZnO}(5 \% \mathrm{PEZnO})\left(\mathrm{WCA}=100.2 \pm 0.5^{\circ}\right)$ is even more hydrophobic than PE, probably due to a surface effect of the nanoparticles. Therefore, the antibacterial activity of the PEZnO nanocomposites cannot be attributed to a surface effect, but only to the antimicrobial properties of $\mathrm{ZnO}$ appointed in previous works. ${ }^{5,720}$

Table 3. Water contact angles of polyethylene and nanocomposites

\begin{tabular}{lc}
\hline Sample & Water contact angle / degree \\
\hline PE & $90.4 \pm 0.3$ \\
$1 \%$ PEZnO & $89.2 \pm 7.7$ \\
$3 \%$ PEZnO & $92.3 \pm 4.3$ \\
$5 \%$ PEZnO & $100.2 \pm 0.5$ \\
\hline
\end{tabular}

PE: polyethylene.

\section{Conclusions}

Nanocomposites of high-density polyethylene with 1, 3, and 5\% nanostructured $\mathrm{ZnO}$ particles, with 32-nm crystal sizes, were successfully obtained by in situ polymerization of ethylene. The thermal stabilities of the nanocomposites were similar to the neat polymer, but the nanocomposites were more crystalline. The good dispersion of $\mathrm{ZnO}$ in the polymer matrix obtained by the use of $i n$ situ polymerization was evident by SEM and TEM and by the good mechanical properties. Polyethylene with only $1 \% \mathrm{ZnO}$ was the most promising among the nanocomposites due to the $13 \%$ superior elastic modulus and elongation at break very similar to the polymer matrix. All the nanocomposites have antimicrobial activities against Staphylococcus aureus (Gram-positive) and Escherichia coli (Gram-negative), showing their potential use as active packaging for food or medicine utensils.

\section{Supplementary Information}

Supplementary data are available free of charge at http://jbcs.sbq.org.br as PDF file.

\section{Acknowledgments}

The authors are grateful to the Conselho Nacional de Desenvolvimento Científico e Tecnológico $(\mathrm{CNPq})$ for grant 302267/2017-4 and to Coordenação de Aperfeiçoamento de Pessoal de Nível Superior (CAPES) (finance code 001) for Giovani Pavoski grant.

\section{Author Contributions}

Giovani Pavoski was responsible for the investigation, writing original draft and validation; Renan Kalikoski, Gustavo Souza, Daniel Baldisserotto, Luiz Fernando W. Brum and Cristiane dos Santos for the investigation; Carlos Bergmann for the conceptualization and resources; Adriano Brandelli for the resources, writing review and editing and validation; Marly Jacobi for the validation; Griselda B. Galland for the conceptualization, formal analysis, funding acquisition, project administration, resources, validation and writing review and editing.

\section{References}

1. Chambhare, S.; Lokhande, G.; Jagtap, R.; Polym. Bull. 2016, 74, 1421.

2. Javed, R.; Usman, M.; Tabassum, S.; Zia, M.; Appl. Surf. Sci. 2016, 386, 319.

3. Sharma, R. K.; Agarwal, M.; Balani, K.; Mater. Sci. Eng., C 2016, 62, 843 .

4. Tankhiwale, R.; Baipai, S. K.; Colloids Surf., B 2012, 90, 16.

5. Espitia, P. J. P.; Soares, N. F.; Coimbra, J. S. R.; Andrade, N. J.; Cruz, R. S.; Medeiros, E. A. A.; Food Bioprocess Technol. 2012, 5, 1447.

6. Barabaszová, K. C.; Holešová, S.; Hundáková, M.; Pazdziora, E.; Ritz, M.; J. Inorg. Organomet. Polym. Mater. 2017, 27, 986.

7. Droval, G.; Aranberri, I.; Germa'n, L.; Ivanov, E.; Dimitrova, E.; Kotsilkova, R.; Verest, M.; Dexpert-Ghys, J.; J. Thermoplast. Compos. Mater. 2014, 27, 268. 
8. Ahmed, J.; Arfat, Y. A.; Al-Attar, H.; Auras, R.; Ejaz, M.; Food Packag. Shelf Life 2017, 13, 20.

9. Ramesan, M. T.; Greeshma, K. P.; Parvathi, K.; Anilkumar, T.; J. Vinyl Addit. Technol. 2019, DOI 10.1002/vnl.21732.

10. Ramesan, M. T.; Siji, C.; Kalaprasad, G.; Bahuleyan, B. K.; Al-Maghrabi, M. A.; J. Polym. Environ. 2018, 26, 2983.

11. Ramesan, M. T.; Nidhisha, V.; Jayakrishnan, P.; Mater. Sci. Semicond. Process. 2017, 63, 253.

12. Hong, J. I.; Winberg, P.; Schadler, L. S.; Siegel, R. W.; Mater. Lett. 2005, 59, 473.

13. Alam, F.; Kumar, A.; Patel, A. K.; Sharma, R. K.; Balani, K.; JOM 2015, 67, 688.

14. Özmihc, F. O.; Balköse, D.; J. Appl. Polym. Sci. 2013, 130, 2734.

15. Mwafy, E. A.; Abd-Elmgeed, A. A.; Kandil, A. A.; Elsabbagh, I. A.; Elfass, M. M.; Gaafar, M. S.; Spectrosc. Lett. 2014, 48, 646.

16. Abou-Kandil, A. I.; Awad, A.; Mwafy, E.; J. Thermoplast. Compos. Mater. 2015, 28, 1583.

17. Rojas, K.; Canales, D.; Amigo, N.; Montoille, L.; Cament, A.; Rivas, L. M.; Gil-Castell, O.; Reyes, P.; Ulloa, M. T.; RibesGreus, A.; Zapata, P. A.; Composites, Part B 2019, 172, 173.

18. Luna, A. S.; Wojnarowicz, G. J.; Rosa, R.; Lojkowski, W.; Leonelli, C.; Acierno, D.; Filippone, G.; Exp. Polym. Lett. 2014, 8,362 .

19. Benabid, F. Z.; Kharchi, N.; Zouai, F.; Mourad, A.-H. I.; Benachour, D.; Polym. Polym. Compos. 2019, 27, 389.

20. Chang, B. P.; Akil, H. M.; Nasir, R. B. M.; Bandara, I. M.; Rajapakse, S.; J. Reinf. Plast. Compos. 2014, 33, 674.

21. Kaminsky, W.; Macromol. Chem. Phys. 1996, 197, 3907.

22. Pavoski, G.; Kalikoski, R.; Souza, G.; Brum, L. F. W.; dos Santos, C.; Markeb, A. A.; dos Santos, J. H. Z.; Font, X.; dell'Erba, I.; Galland, G. B.; Eur. Polym. J. 2018, 106, 92.

23. Pavoski, G.; Baldisserotto, D. L. S.; Maraschin, T.; Brum, L. F. W.; dos Santos, C.; dos Santos, J. H. Z.; Brandelli, A.; Galland, G. B.; Eur. Polym. J. 2019, 117, 38.
24. Guaglianoni, W. C.; Garcia, A. P.; Basegio, T. M.; Bergmann, C. P.; Tecnol. Metal., Mater. Min. 2015, 12, 153.

25. WinFit, v. 1.2.1; Krumm, Institut fur Geologie, Scholssgarten, Erlangen, Germany, 1997.

26. Provenzi, C.; Collares, F. M.; Cuppini, M.; Samuel, S. M. W.; Alves, A. K.; Bergmann, C. P.; Leitune, V. C. B.; Clin. Oral Invest. 2018, 22, 2209.

27. Onisei, S.; Badilita, V.; Stoiciu, F.; Velea, T.; Predica, V.; Lupu, C.; Butu, M.; Moldovan, P.; Rev. Chim. 2012, 63, 591.

28. Fagerlund, G.; Mater. Constr. 1973, 6, 239.

29. Minick, J.; Moet, A.; Baer, E.; Polymer 1995, 36, 1923.

30. Surftens 3.0; OEG, Frankfurt, Germany. Available at www. oeggmbh.com, accessed in March 2020.

31. ASTM D638-10: Standard Test Method for Tensile Properties of Plastics; ASTM International, West Conshohocken, PA, 2010.

32. Adamson, A. W.; Gast, A. P.; Physical Chemistry of Surfaces; Interscience: New York, USA, 1967, p. 180.

33. Gopakumar, T. G.; Pagé, D. J. Y. S.; Polym. Eng. Sci. 2004, 44, 1162.

34. Milani, M. A.; Quijada, R.; Basso, N. R. S.; Graebin, A. P.; Galland, G. B.; J. Polym. Sci., Part A: Polym. Chem. 2012, 50, 3598.

35. Milani, M. A.; González, D.; Quijada, R.; Basso, N. R. S.; Cerrada, M. L.; Azambuja, D. S.; Galland, G. B.; Compos. Sci. Technol. 2013, 84, 1.

36. Pavoski, G.; Maraschin, T.; Milani, M. A.; Azambuja, D. S.; Quijada, R.; Moura, C. M.; Basso, N. R. S.; Galland, G. B.; Polymer 2015, 81, 79.

37. Kaminsky, W.; Bark, A.; Speihl, R.; Moller-Lindenhof, N.; Niedoba, S. In Transition Metals and Organometallics as Catalyst for Olefin Polymerization; Kaminsky, W.; Sinn, H., eds; Springer: Berlin, Germany, 1988, p. 291.

38. Odian, G.; Principles of Polymerization, $4^{\text {th }}$ ed.; Wiley: Hoboken, New Jersey, USA, 2004, p. 19.

39. Zou, H.; Wu, S.; Shen, J.; Chem. Rev. 2008, 108, 3893.

Submitted: December 19, 2019

Published online: March 13, 2020 